\title{
Cervical spine instability and canal stenosis caused by rheumatoid arthritis
}

\author{
Eko Agus Subagio' \\ Seok Woo Kim ${ }^{2}$ \\ 'Spine Division, Department of Neurosurgery, \\ dr. Soetomo General Hospital, \\ Faculty of Medicine, Universitas Airlangga, \\ Surabaya, Indonesia \\ ${ }^{2}$ Spine Center, Hallym University Sacred Heart \\ Hospital, Hallym University, 896 Pyeongchon- \\ dong, Dongan-gu, Anyang-si, Gyeonggi-do 43I- \\ 070, Korea
}

Cite this article:

Subagio EA, Woo Kim S. Cervical spine instability and canal stenosis caused by rheumatoid arthritis. Neurologico Spinale Medico Chirurgico. 2020.3(3):97-102.

DOI: 10.36444/nsmc.v3i3.II5

Corresponding author:

Eko Agus Subagio

Spine Division, Department of Neurosurgery,

Dr. Soetomo General Academic Hospital,

Gedung Pusat Diagnostik Terpadu $5^{\text {th }}$ floor.

Faculty of Medicine, Universitas Airlangga, St.

Mayjen. Prof. Dr. Moestopo 6-8,

Surabaya 60286 - Indonesia

easnsurg@yahoo.com

\begin{abstract}
Rheumatoid arthritis (RA) is an inflammatory autoimmune disease that impacts on weakening ligaments, synovial arthritis and cartilage damage. The effect that can occur is instability and neural compression in the upper and sub-axial cervical. The prevalence of atlantoaxial instability (AAI) is around $40-80 \%$ among rheumatoid patients, but it is interesting to examine the clinical symptoms that are not so visible despite radiological instability confirmed on the cervical spine. However, once the clinical symptoms of myelopathy occur, the mortality rate will increase sharply.

We report a case of a 66-years old female who was admitted to our hospital with gait disturbance and weakness of her lower extremities. Radiographic evaluation of the cervical spine showed erosive destruction of the odontoid process of $\mathrm{C} 2$, anterior atlantoaxial subluxation, and thickened yellow ligaments from C3 to C7. Surgery was performed by removal of the posterior arch of $\mathrm{C} 1$ and laminectomy $\mathrm{C} 3$ to $\mathrm{C} 7$, posterior occipito-cervical screw fixation from $\mathrm{C} 3$ to $\mathrm{C} 7$, combined with atlantoaxial transpedicular screw fixation. A sterno sub-occipitomandibular immobilization (SOMI) orthosis was applied for postoperative immobilization for 12 weeks. Improvement of motoric status noted after surgery.
\end{abstract}

Keywords: Rheumatoid arthritis, Atlantoaxial instability, Sub-axial subluxation, Cervical canal stenosis

\section{Introduction}

Rheumatoid arthritis (RA) is a chronic inflammatory process that causes symmetrical synovitis, resulting in deformities in the hands and feet's small joints. ${ }^{1}$ The next most common abnormality is the cervical spine in $36-86 \%$ of all RA cases. Fortunately, biological therapy such as 17 infliximab (IFX) as first-line biologic treatment and 17 tocilizumab (TCZ) as a second-line biologic treatment combined with methotrexate (MTX) on rheumatoid arthritis can decrease cervical involvement to $15-30 \%{ }^{2,3}$ However, medical treatment is only preventative, if cervical abnormalities have given symptoms, then fusion surgery should be considered to stop the disease's progression. ${ }^{4}$ Clinical manifestation range from occipital neuralgia, sensory disturbance, muscle 
weakness, quadriplegia, and sudden death. ${ }^{5}$ Inflammation is a significant factor in this disorder, so the levels of C-reactive protein (CRP) in the diagnosis of rheumatoid arthritis are the risk factors for the development of atlantoaxial subluxation. ${ }^{6}$ The high incidence of cervical instability in rheumatoid arthritis recommends that we should routinely screen cervical instability for rheumatoid arthritis patients. ${ }^{7}$

Inflammatory synovial proliferation causing ligaments tendinous tissues laxity and bone erosion, resulting in excessive movement of the cervical joints. Damage to the transverse ligament and especially alar ligament causes a significant increase in Anterior Atlanto Dental Interval (AADI). ${ }^{8}$ Increasing sliding motion between atlas and axis will develop atlantoaxial subluxations (AAS) 65\%. Facet ligament laxity and joint surface destruction at the $\mathrm{C} 3$ to $\mathrm{C} 7$ and interspinous processes ligaments laxity create subaxial subluxation (SAS) observed in 20\% and cranial settling describe in $15 \% .{ }^{9}$ Patient may have one subluxation (one of the following: atlantoaxial subluxations-AAS or Subaxial subluxation-SAS or basilar invagination/upward migration of the dens/Cranial settling of odontoid process), or combination of two or three types of involvement. ${ }^{10}$

Medullary brainstem compression may be caused by cranial settling of odontoid process or pannus. Spinal cord compression may be caused by dynamic compression as well. The risk of irreversible paralysis is increased if the posterior atlanto-dental interval (PADI) is $14 \mathrm{~mm}$ or less. ${ }^{5}$ Neural compression may progress and cause death in $10 \%$ of patients with cervical rheumatoid arthritis in post mortem studies. ${ }^{11}$ Essential discussions have existed about the management in patients whom radiologically confirmed cervical instability in the absence or mild neck pain and neurological symptoms. ${ }^{12}$ To avoid unnecessary surgery, some of the authors accept conservative management, cervical orthosis, and symptomatic treatment. This option may lead to late interventions, which has proved to make a worse outcome. Once myelopathy is caused by cranial settling occurs, the mortality rate increases significantly, even after adequate surgery with decompression and stabilization. Once it turns to myelopathy, $50 \%$ will die in a year. ${ }^{12}$

In this case report, we describe a successfully managed patient with rheumatoid arthritis who developed erosive destruction of the odontoid process, anterior atlantoaxial subluxation, superior migration of odontoid, sub-axial subluxation, and cervical canal stenosis.

\section{Case report}

A sixty-six years old female was admitted with gait disturbance, weakness of bilateral lower extremities, clumsiness of both hands, and decreased sensation of lower legs. On her past history, she had an anterior corpectomy and fusion of Th12 and laminectomy of L2-5 five months before admission, due to a compression fracture combined with a severe lumbar canal stenosis. She also underwent bilateral knee arthroplasty two years ago. No complication-related events were noted in those surgeries.

Physical examination revealed contracture of all fingers, bilaterally, in a flexed position and ulnar deviation. Hoffman sign, grip and release test, and finger escape sign were all positive. Manual muscle testing revealed generalized muscle weakness. Other physical examinations were unremarkable.

Laboratory studies revealed an elevated erythrocyte sedimentation rate $(97 \mathrm{~mm} / \mathrm{h})$ and an elevated C-reactive protein (CRP) level of $97 \mathrm{mg} / \mathrm{dL}$. The serological test for rheumatoid factor was positive. Other lab examinations reveal normal results.

Radiographic evaluation of the cervical spine showed erosive destruction of the odontoid process of $\mathrm{C} 2$, anterior atlantoaxial subluxation, and thickened yellow ligaments from C3 to C7. The anterior atlanto-dental interval was $7.38 \mathrm{~mm}$ (normal $\leq 3 \mathrm{~mm}$ ). The posterior atlanto-dental interval was $9.49 \mathrm{~mm}$ (normal $\geq 14 \mathrm{~mm}$ ). From flexion-extention radiograph show that it is a non-fix subluxation.

There was $10.55 \mathrm{~mm}$ superior migration of odontoid as measured with the method of Ranawat (normal Ranawat line for man is $15 \pm 2 \mathrm{~mm}$, the shorter the ranawat line, the greater the cranial settling $)^{9}$ and odontoid tip above McRae's line. Subaxial subluxation demonstrated by 4.35 $\mathrm{mm}$ posterior listhesis of $\mathrm{C} 3$ to $\mathrm{C} 4$ (normal $<3 \mathrm{~mm}$ ), with a $6.67 \mathrm{~mm}$ canal diameter.

Symptoms do not improve with conservative treatment and get worse over time. The operation is carried out in a prone position. The sub occipital plate is installed first. Then with the help of the head frame the neck is positioned slightly in extension so that there is reduction of the anterior distance of $\mathrm{C} 1 \mathrm{C} 2$. The transarticular atlantoaxial screw was chosen in order to maintain the improved distance of $\mathrm{C} 1 \mathrm{C} 2$ without adding a screw to $\mathrm{C} 1$, because the $\mathrm{C} 1$ screw head would be difficult to fit to the alignment rod from the suboccipital plate to $\mathrm{C} 2 \mathrm{head}$ screw. According to Kraus's opinion, if there is a subaxial subluxation and the construct involves the suboccipital then a longer construct is carried out. In this patient, lateral mass screws were placed from $\mathrm{C} 3$ to $\mathrm{C} 7$, and total laminectomy decompression of $\mathrm{C} 3$ to $\mathrm{C} 6$ done, which was then used as an autologous bone graft. Taking into account the individual condition of the patient in assisting post-operative rehabilitation, it was decided to maintain one segment of the segmental movement rather than fusion to $\mathrm{T} 1$. 


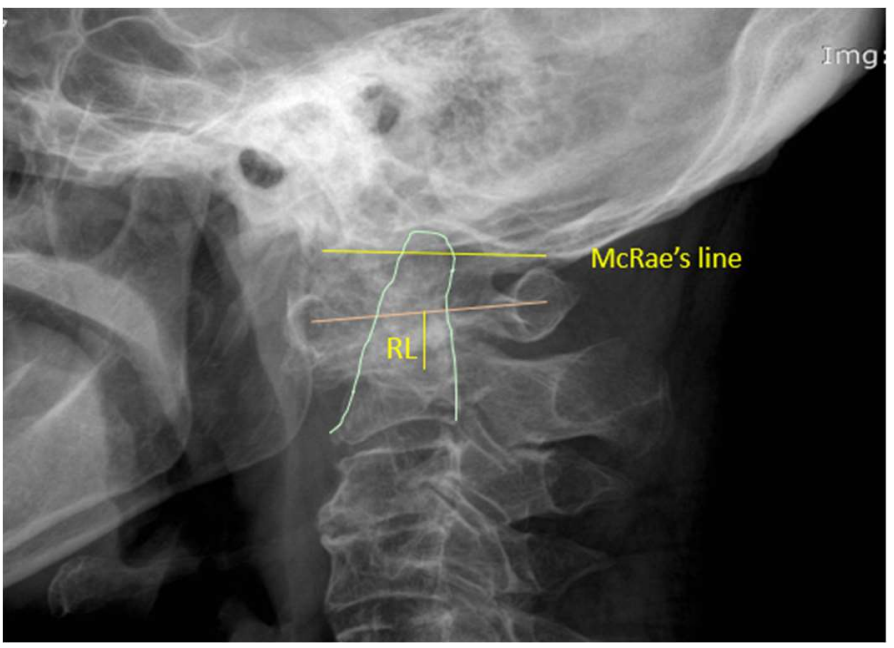

Figure 1. Pre Operative Radiograph of Craniovertebral Junction Lateral View. Shows superior migration of odontoid tip above McRae's line. And superior migration of odontoid (Ranawat's method measurement): $10.55 \mathrm{~mm}$. *The McRae's line: a line drawn that connects the posterior (opisthion) and anterior (basion) margin of the foramen magnum. If the tip of odontoid is above this line it is concerning for a possible basilar invagination (normally 5 mm below this line).

**RL: Ranawat's line: perpendicular distance between center of sclerotic C2 and the line drawn along the axis of C1 (normally $15 \mathrm{~mm} \pm 2 \mathrm{~mm}$ ).

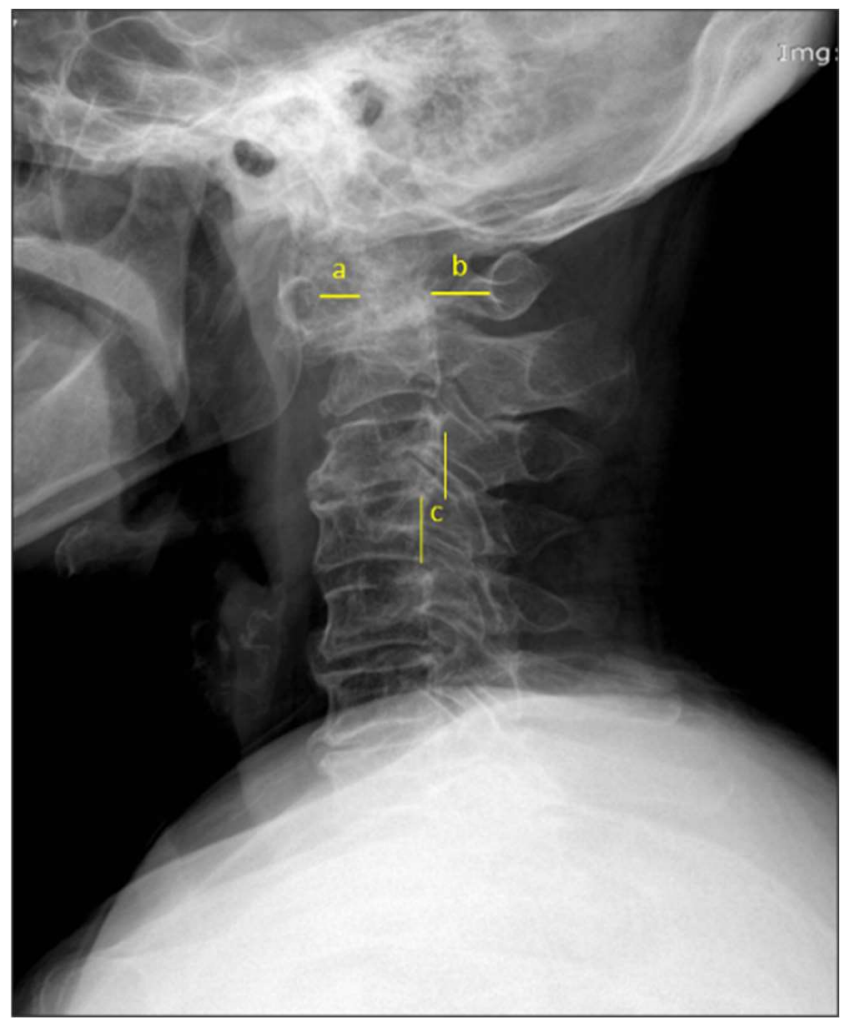

Figure 2. Pre Operative Radiograph of Craniovertebral Junction Lateral View. (a) Anterior Atlanto Dental Interval-AADI: $7.38 \mathrm{~mm}$. (b) Posterior Atlanto Dental Interval-PADI: $9.49 \mathrm{~mm}$ (normal $\geq 14 \mathrm{~mm}$ ). (c) Subaxial subluxation demonstrated by posterior listhesis of C3 to C4: $4.35 \mathrm{~mm}$ (normal $\leq 3 \mathrm{~mm})$
A sterno-suboccipito mandibular immobilization (SOMI) orthosis was applied as postoperative immobilization for 12 weeks. She experienced gradual improvements in motoric status after the surgery.

\section{Discussion}

One of the important things is to establish the diagnosis. The diagnosis of AAS should be made by radiography examination with the patient hanging her head freely in flexion. In $50 \%$ of the cases, the subluxation is missed when the examination is made in a neutral position. ${ }^{6}$

Lateral cervical radiograph examination in extension is needed to find atlantoaxial movement in the posterior direction. Thus we can determine whether atlantoaxial subluxation is fixed or non-fixed; it may determine therapeutic management. MRI is the best for evaluating neural compression, and the maximum extent possible of the subluxation must be considered. The apparent diffusion coefficient may be used as an indicator of spinal cord compression. ${ }^{13}$ Soft tissue abnormalities, odontoid erosions, and AAS can be seen more clearly on 3T MRI. ${ }^{14}$ However, the degree of magnitude of AAS often appears lighter when compared to dynamic radiography. ${ }^{15}$

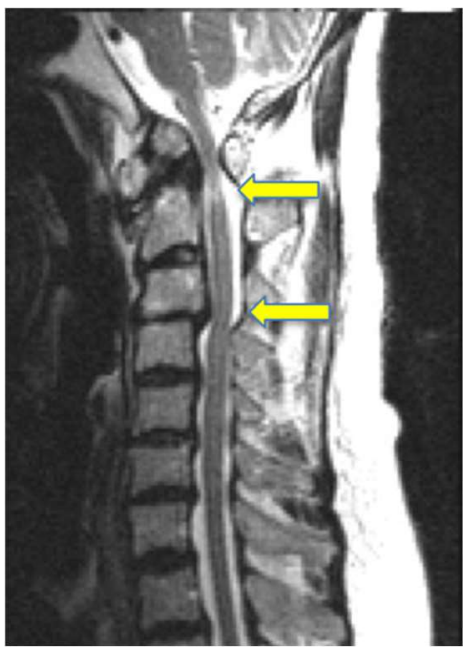

Figure 3. Pre Operation MRI assessment reveals spinal cord signal changed at C1C2 level, indicates a significant spinal cord compression. Stenosis at level C34 that occurs due to anterior listhesis C3 to C4, which can be exacerbated by flexion-extension movements.

The pannus will disappear after an immobilization of the atlantoaxial segment, and no progression of the upward migration of the dens despite the unchanged systemic course of the disease during the 5year follow-up. ${ }^{12}$ And there were no significant increase in the Redlund-Johnell index too. ${ }^{16}$ Early atlantoaxial fusion seemed to 
prevent the development of superior migration of the odontoid, and when occipitocervical fusion is necessary and early subaxial subluxation is present, longer fusions or occipitocervicothoracic fusion should be strongly considered. ${ }^{10}$ After atlantoaxial fusion, we should always alert to the possibility of adjacent segment disease, particularly at the level of $\mathrm{C} 3-\mathrm{C} 4 .{ }^{17}$

A prophylactic posterior fusion in severe AAS, even in the absence of neurological compromise will decrease the mortality rate, relief from pain, and produce significantly better neurological and functional recovery, a significantly lower radiological degree of vertical translocation and atlantoaxial subluxation, and provide a better longterm result. ${ }^{18}$

Atlantoaxial fusion in inflammatory induced instability aims to eliminate pain and prevent continuous compression of the medulla by eliminating instability and atlantoaxial subluxation, also to prevent progression of the deformity and elimination of tissue destruction.

There are various techniques used for $\mathrm{C} 1 \mathrm{C} 2$ fusion. The Gallie procedure, consists of an autologous bone graft fixed with a wire loop to the posterior part of the atlas and the spinous process of the axis, but it lacks resistance to translational displacement. ${ }^{19}$ Compared to the C1C2 screw-rod construct, the Gallie technique can reduce postoperative pain faster, shorten operating time, reduce intraoperative bleeding, use less fluoroscopy, and hospital cost effective. ${ }^{20}$

The Brooks procedure when compared to galli procedure, has better rotational stability by its bilateral laminar fixation. Two autologous bone grafts are placed posteriorly between the atlas and the right and left lamina of the axis, enhanced with clamps and hooks. ${ }^{19}$

A three-point atlantoaxial fixation is a reliable method. It consists of transarticular screw fixation, by crossing the atlantoaxial joints bilaterally and augmented by a bone graft. It will create a threepoint atlantoaxial construction. Atlantoaxial transarticular screw fixation and $\mathrm{C} 1$ lateral mass- $\mathrm{C} 2$ pedicle screw fixation has same excellent outcome, but in the sake of blood loss and operation time transarticular screw has better result. ${ }^{21}$

The fusion rate in occipitocervical fusion $(90.1 \%)$ is better than atlantoaxial fusion $(80 \%)$. However, there is a difference in the occurrence of distal adjacent segment disease where $36 \%$ of post occipitocervical fusion occurs subaxial subluxation, which requires an operative procedure on average 2.6 years later. ${ }^{10,21-24}$ Whereas in the atlantoaxial fusion group, $5 \%$ occurred subaxial subluxation, which requires operative procedure an average of 9-years post fusion. As a consequence, if there are already visible signs of subaxial subluxation and occipitoservical fusion is needed, then a longer fusion or occipitocervicothoracic fusion should be strongly considered. ${ }^{10}$

In the case of superior migration of the odontoid, fixed altocantoaxial subluxation with anterior compression of the cervical cord, an anterior decompression-odontoidectomy and a posterior fixation are necessary. ${ }^{25}$

Several devices are available for occipitocervical fusion. Wire or screw to fix the bone graft, contoured rod, and plates. Currently, a newly design Y-plate combined with transarticular atlantoaxial screw fixation and additional bone grafting underneath the plate provides reliable stability. Sub axial cervical laminectomy has done, augmented by lateral mass fusion technique using a polyaxial screw to prevent kyphosis deformity. ${ }^{26}$ For arthrodesis, it must be extended to the lower cervical spine, and a long version of the plate may be fixed by lateral mass screw. We experienced a strong fixation and good stability with this sub-occipito cervical Y plate design.

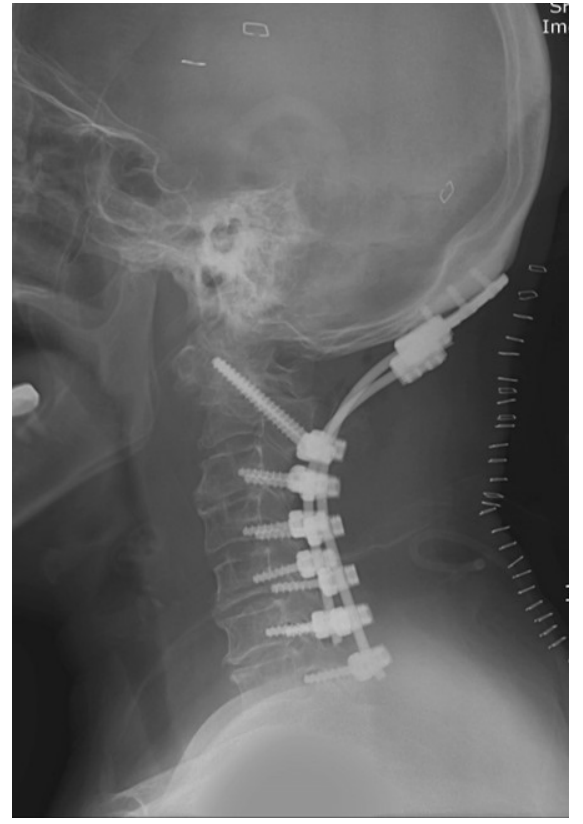

Figure 4. Post Operative Radiograph Lateral view. Surgery has been done by removal of posterior arch of $C 1$, subaxial cervical vertebrae C3456 total laminectomy and posterior occipito-cervical screw fixation of C3-C7, combined with trans articular atlantoaxial screw fixation.

\section{Conclusion}

A thorough evaluation of rheumatoid arthritis with cervical canal involvement is essential. The therapeutical approaches are conservative and surgical. In cases where cervical rheumatoid arthritis develops neurological symptoms, the surgical approach may help the patient to reach a better outcome. 


\section{Acknowledgment}

No acknowledgment

\section{References}

1. Wolfe J, Wolfe J, Visser HJ. Perioperative Management of the Rheumatoid Patient. Clinics in Podiatric Medicine and Surgery. 2019;36(1):115-130. DOI: 10.1016/j.cpm.2018.08.005

2. Janssen I, Nouri A, Tessitore E, et al. Cervical myelopathy in patients suffering from rheumatoid arthritis - a case series of 9 patients and a review of the literature. Journal of Clinical Medicine. 2020;9(3):811. DOI: $10.3390 / \mathrm{jcm} 9030811$

3. Takahashi S, Suzuki A, Koike T, et al. Current prevalence and characteristics of cervical spine instability in patients with rheumatoid arthritis in the era of biologics. Modern Rheumatology. 2014;24(6):904-909. DOI: 10.3109/14397595.2014.895123

4. Gillick JL, Wainwright J, Das K. Rheumatoid arthritis and the cervical spine: a review on the role of surgery. International Journal of Rheumatology. 2015;2015:252456. DOI: 10.1155/2015/252456

5. Neva M, Häkkinen A, Mäkinen $\mathrm{H}$, et al. High prevalence of asymptomatic cervical spine subluxation in patients with rheumatoid arthritis waiting for orthopaedic surgery. Annals of the Rheumatic Diseases. 2006;65(7):884-888. DOI: 10.1136/ard.2005.042135

6. Na MK, Chun HJ, Bak KH, et al. Risk factors for the development and progression of atlantoaxial subluxation in surgically treated rheumatoid arthritis patients, considering the time interval between rheumatoid arthritis diagnosis and surgery. Journal of Korean Neurosurgical Society. 2016;59(6):590-596. DOI: 10.3340/jkns.2016.59.6.590

7. Cunningham S. Upper cervical instability associated with rheumatoid arthritis: a case report. Journal of Manual and Manipulative Therapy. 2016;24(3):151-157. DOI: 10.1179/2042618614Y.0000000096

8. Meyer C, Bredow J, Heising E, et al. Rheumatoid arthritis affecting the upper cervical spine: Biomechanical assessment of the stabilizing ligaments. BioMed Research International, 2017;2017(5):1-7. DOI: $10.1155 / 2017 / 6131703$

9. Mańczak M, Gasik R. Cervical spine instability in the course of rheumatoid arthritis -imaging methods. Reumatologia. 2017;55(4):201-207. DOI: 10.5114/reum.2017.69782

10. Mikulowski P, Wollheim F, Rotmil P, et al. Sudden Death in Rheumatoid Arthritis with Atlanto-axial Dislocation. Acta Medica Scandinavica. $\quad$ 2009;198(1-6):445-451. DOI: $\quad$ 10.1111/j.09546820.1975.tb19573.x

11. Grob D. Atlantoaxial immobilization in rheumatoid arthritis: a prophylactic procedure?. European Spine Journal. 2000;9(5):404-
409. DOI: $10.1007 / \mathrm{s} 005860000174$

12. Mańczak M, Pracoń G, Sudoł-Szopińska I, et al. Apparent diffusion coefficient as an indicator of spinal cord compression due to anterior atlanto-axial subluxation in rheumatoid arthritis patients. European Spine Journal. 2019;28(10):2352-2358. DOI: 10.1007/s00586-01906058-2

13. Oláh C, Kardos Z, Kostyál L, et al. Assessment of cervical spine involvement in rheumatoid arthritis patients in the era of biologics: a real-life, cross-sectional MRI study. Rheumatology International. 2020;40(6):915-921. DOI: 10.1007/s00296-020-04549-w

14. Laiho K, Soini I, Kautiainen H, et al. Can we rely on magnetic resonance imaging when evaluating unstable atlantoaxial subluxation?. Annals of the Rheumatic Diseases. 2003;62(3):254256. DOI: 10.1136/ard.62.3.254

15. Morizono Y, Sakou T, Kawaida H. Upper Cervical Involvement in Rheumatoid Arthritis. Spine. 1987;12(8):721-725. DOI: 10.1097/00007632-198710000-00001

16. Kraus DR, Peppelman WC, Agarwal AK, et al. Incidence of subaxial subluxation in patients with generalized rheumatoid arthritis who have had previous occipital cervical fusions. Spine. 1991;16(10):S486-S489. DOI: 10.1097/00007632-19911000100006

17. Clarke MJ, Cohen-Gadol AA, Ebersold MJ, et al. Long-term incidence of subaxial cervical spine instability following cervical arthrodesis surgery in patients with rheumatoid arthritis. Surgical Neurology. 2006;66(2):136-140. DOI: 10.1016/j.surneu.2005.12.037

18. Tanaka N, Sakahashi H, Hirose K, et al. Results after 24 years of prophylactic surgery for rheumatoid atlantoaxial subluxation. Journal of Bone and Joint Surgery - Series B. 2005;87(7):955-958. DOI: 10.1302/0301-620X.87B7.1586

19. Alshafai N, Kramarz A, Behboudi M. Insights into the Past and Future of Atlantoaxial Stabilization Techniques. Acta Neurochirurgica Supplement. 2019;:265-271. DOI: 10.1007/978-3319-62515-7_38

20. Yuan B, Zhou S, Chen X, et al. Gallie technique versus atlantoaxial screw-rod constructs in the treatment of atlantoaxial sagittal instability: a retrospective study of 49 patients. Journal of Orthopaedic Surgery and Research. 2017;12(1). DOI: 10.1186/s13018-017-0607-y

21. Rajinda $\mathrm{P}$, Towiwat $\mathrm{S}$, Chirappapha $\mathrm{P}$, et al. Comparison of outcomes after atlantoaxial fusion with $\mathrm{C} 1$ lateral mass- $\mathrm{C} 2$ pedicle screws and C1-C2 transarticular screws. European Spine Journal. 2017;26(4):1064-1072. DOI: 10.1007/s00586-016-4829-1

22. Herzog JP, Zarkadis NJ, Prabhakar G, et al. Biomechanical comparison of a novel $\mathrm{C} 1$ posterior U-construct with four other techniques in a C1-C2 fixation model. J Orthop. 2018;15(2):741-5. DOI: 10.1016/j.jor.2018.05.010 
23. Papagelopoulos $\mathrm{P}$, Currier B, Hokari $\mathrm{Y}$, et al. Biomechanical Comparison of $\mathrm{C} 1-\mathrm{C} 2$ Posterior Arthrodesis Techniques. Spine. 2007;32(13):E363-E370. DOI: 10.1097/brs.0b013e318060cc65

24. Naderi S, Crawford N, Song G, et al. Biomechanical Comparison of C1-C2 Posterior Fixations. Spine. 1998;23(18):1946-1955. DOI: 10.1097/00007632-199809150-00005
25. Kandziora F, Mittlmeier T, Kerschbaumer F. Stage-related surgery for cervical spine instability in rheumatoid arthritis. European Spine Journal. 1999;8(5):371-381. DOI: 10.1007/s005860050190

26. Bajamal $\mathrm{AH}$, Kim SH, Arifianto MR, et al. Posterior surgical techniques for cervical spondylotic myelopathy: WFNS spine committee recommendations. Neurospine. 2019;16(3):421-434. DOI: $10.14245 /$ ns. 1938274.137 